\title{
Recent Trends in the Evaluation of Functional Foods
}

\author{
David A. WHITMORE* \\ Director, Alimenta Ltd., 15 Meadoway, Hartwell Aylesbury, HP17 8QJ, U.K. \\ Presented at the International Conference of Intestinal Bacteriology (ICIB 2001), held in Tokyo, July 5-6, 2001. Received for \\ publication, June 8, 2001
}

\begin{abstract}
The specific health benefits of individual food components have been recognised for centuries, but only relatively recently has there been a determined effort by pioneering individuals in Countries such as Japan, to take advantage of the huge public health benefits that are on offer. It is a sad fact that in almost all Countries that have adopted Legislation or Codes of Practice, it is the pressure derived from exaggerated health claims on food products that lead to controls. Absurd product health claims created with little or no regard for the scientific evidence results in the Authorities fighting a rearguard action to limit claims, rather than adopting an initial neutral attitude and approach that would lead to fresh thinking. In the European Economic Community, current National practices and legislation in the 15 Member States effectively create different approaches towards food fortification, food supplements, herbal products and the availability of non-prescription products. In the absence of a specific Directive from Brussels, it is not surprising that the majority of EU Member States have in place, or are currently working on National Codes of Practice in an attempt to control foods that carry health messages. In an attempt to harmonise the basic requirements for controls on functional foods, the CIAA has produced a pan-European document that sets out the principle requirements. We also need to consider the effect that officially recognising health claims for food will have on specialised product sectors where a surprising degree of freedom already exists for health claims. In my paper I will compare individual Codes of Practice and Legislation and discuss representative examples of food and supplement products. I will point out the current advantages for some market sectors, together with the failings in well-established legislation that can prevent the marketing of bona fide foods with health claims.
\end{abstract}

Key words: health claims; food legislation; Europe

The concept of a 'functional food' is very simple and their definition can be very straightforward, but as with most simple and straightforward ideas, the reality can prove to be very difficult to implement. When dealing with food products that have evolved in accordance with established legal rules that have changed very little for a number of years, resistance to change, without a political will is remarkable, although National strategies aimed at improving public health are published regularly.

If we add in;

- a medical connotation;

- the equivocal interpretation of some good and some very poor science;

- the reluctance for the Authorities to act for fear of getting it wrong;

together with:

- Corporate marketing impatience; and

- the potential for large Corporate profits.

we then have the ideal recipe for the proliferation of food and food supplement products making unsubstantiated health and medicinal claims. We have to be aware

*Corresponding author. Mailing address: Alimenta Ltd., 15 Meadoway, Hartwell Aylesbury, HP17 8QJ, U.K. Phone: +44-1296-748-622. Fax. +44 1296-748-525. E-mail: david.whitmore@alimenta.co.uk that consumers are interested in foods that provide specific health benefits and that the food industry has always responded to that interest. Foods with health claims result and food legislation will develop or has to adapt in response to that demand. Delays by the Authorities will only cause confusion and result in the proliferation of products with illegal health claims and labelling.

The specific health benefits of individual food components have been recognised for centuries. However, only relatively recently has there been a determined effort by pioneering individuals in Countries such as Japan, to take advantage of the huge public health benefits that are on offer, and the Foods for Specified Health Uses (FOSHU) (1) provisions have set a valuable example to follow. It is a fact, and I hope I am not being too cynical, that the lifespan of for example, a typical Government administration is far shorter than the time needed to demonstrate health benefits that can be derived by dietary means. Why, therefore, should there be a political will to put in place measures that may be seen as unpopular since they may be interpreted as interference with the National diet, for very little or no short-term benefit?

So how has the change in attitude towards functional 
foods that is now coming about in a number of Countries been effected? In almost all Countries that have adopted an imaginative interpretation of existing food legislation or have evolved Codes of Practice for functional foods, it is the pressure derived from exaggerated health claims on food products that have lead to controls. Taking the European Union (EU) as an example and at the moment (May 2001), of the 15 Member States there are 9 (Austria, Belgium, Denmark (2), Finland, France, The Netherlands (3), Spain, Sweden and the United Kingdom (4)) that either permit food health claims following negotiation with the Authorities, or have Guidelines or published Codes of Practice. A further 3 Member States (Germany, Ireland and Portugal) are setting up, or currently negotiating with representative groups to set up functional food Working Groups that will examine the legality of food health claims and their national implementation. Elsewhere, in the Council of Europe (CoE), Guidelines to control food health claims have also been drawn up (5). These $\mathrm{CoE}$ Guidelines will be submitted at the end of May 2001 to the $\mathrm{CoE}$ Committee of experts on nutrition, food safety and consumer health, for adoption.

Faced with these National and International initiatives, the European Commission has decided that food health claims is now a priority, but the Discussion Paper due to be published by the start of March 2001 is still eagerly awaited (as at May 2001). This delay may in turn lead to a delay in the stated November 2001 implementation date, or result in a shortened consultation period. However, with the number of EU Member States National examples of Guidelines or adopted positions on functional foods already very clearly stated, the Commission Discussion Paper will hopefully reproduce the many useful and well argued scenarios that will permit food health claims and suggest changes to existing laws that currently prohibit the dissemination of vital health messages.

There is clearly a need for controls on foods that carry health messages, but is the existing food legal framework in those Countries, especially in Europe sufficient to control health claims? It is apparent that the supporting scientific evidence needs to be well defined and carried out to accepted standards, but a legal or other recognised reference point is needed to allow Agencies, the Authorities and the Food Industry to work together. Product innovation will only progress if food companies can capitalise on their scientific advances, and be allowed to communicate the benefits of functional foods by clear and concise health messages. In addition, we have to be aware of several borderlines where health and medical claims may meet.

In the absence of the EU Commission Discussion Paper, Table 1 sets out the current European situation for those Member States that have drawn up Guidelines or Codes of Practice, or have adopted a particular stance towards functional foods. It is interesting to note that some Countries such as France and The Netherlands have devised their controls by drawing together, and encouraging debate between the Food Industry, Retailers, Consumer Associations, Academic Scientists, and the Authorities. The Authorities in Finland felt confident enough to progress with their controls without the need to involve other Groups, but most Countries that have derived Codes or Guidelines have involved three or four of these Groups.

Even in those markets that have an established functional food market and a perceived liberal approach to the marketing of health messages, over enthusiastic marketing still exists. The result is that absurd product health claims created with little or no regard for the scientific evidence or a disregard for the established regulations can result in problems for the industry as a whole. In the US, the Food \& Drug Administration (FDA) has recently (January 2001) warned functional food manufacturers of their obligations under the Federal Food, Drug \& Cosmetic Act (the Act). The FDA are concerned (6) that some plant extracts and Novel Ingredients added to foods with consequential claims contravened the Act and were not GRAS (Generally Regarded as Safe) self-determined. Health claims are permitted by means of authoritative statements with due notification. Otherwise claims "characterising the relationship between a substance and a disease or healthrelated condition' are only permitted to be made in food labelling if a petition has been filed with the FDA, otherwise the product may be regarded as a drug. In raising these issues the FDA in conjunction with the US General Accounting Office seem to be indicating that the legal framework that controls functional foods and food supplements may need to be strengthened, in particular to prevent the marketing of functional foods as Food Supplements (St. John's Wort, Gingko biloba) were GRAS affirmation is not required.

It is sometimes forgotten that claims are essential to the marketing of a wide range of very different food and pharmaceutical products and confusion often results by perceived cross over claims that affect many reserved sectors; it is not just between food and pharmaceuticals where the so-called 'grey area' claims for functional foods can cause problems. Figure 1 illustrates the many different interfaces and potential grey 


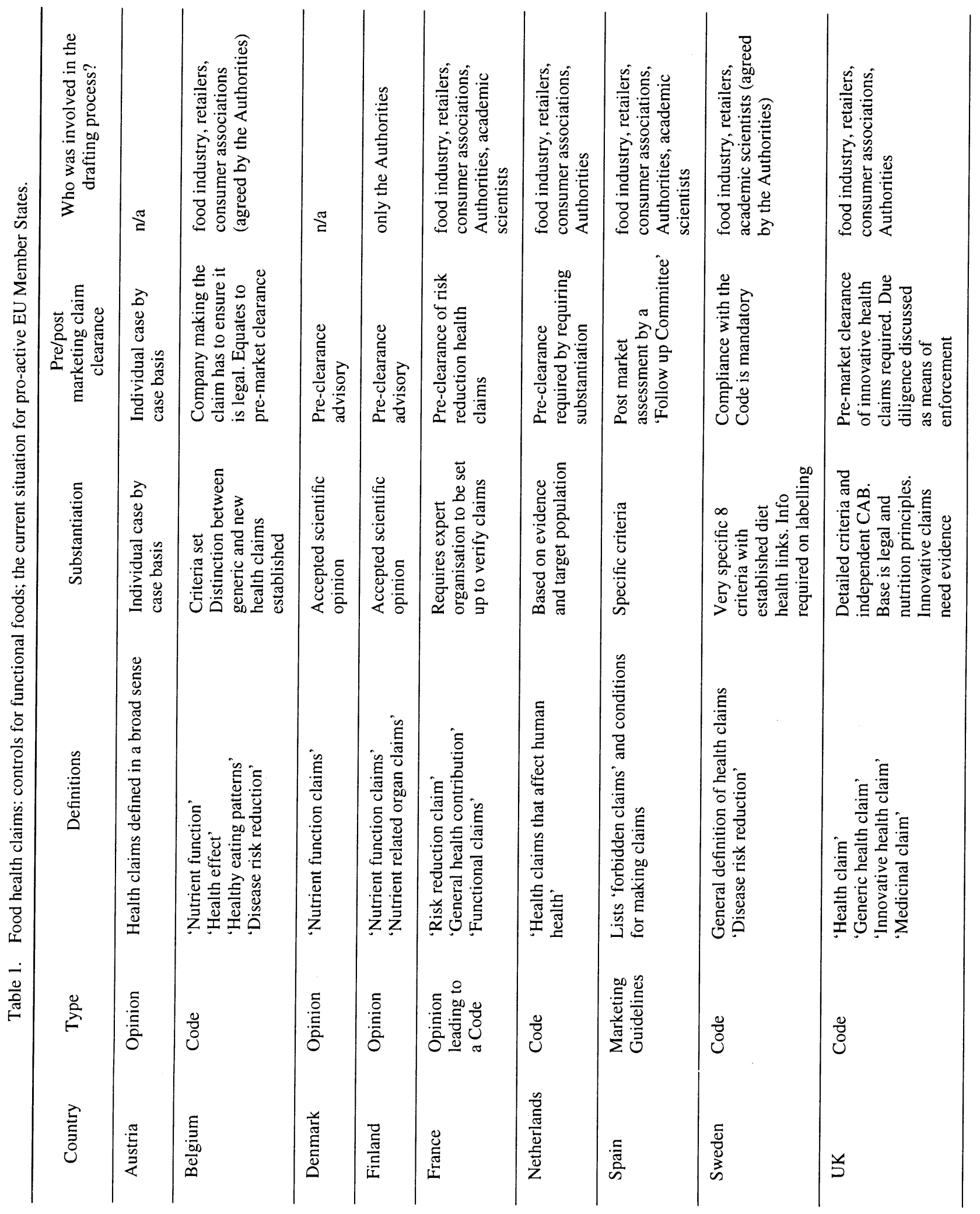




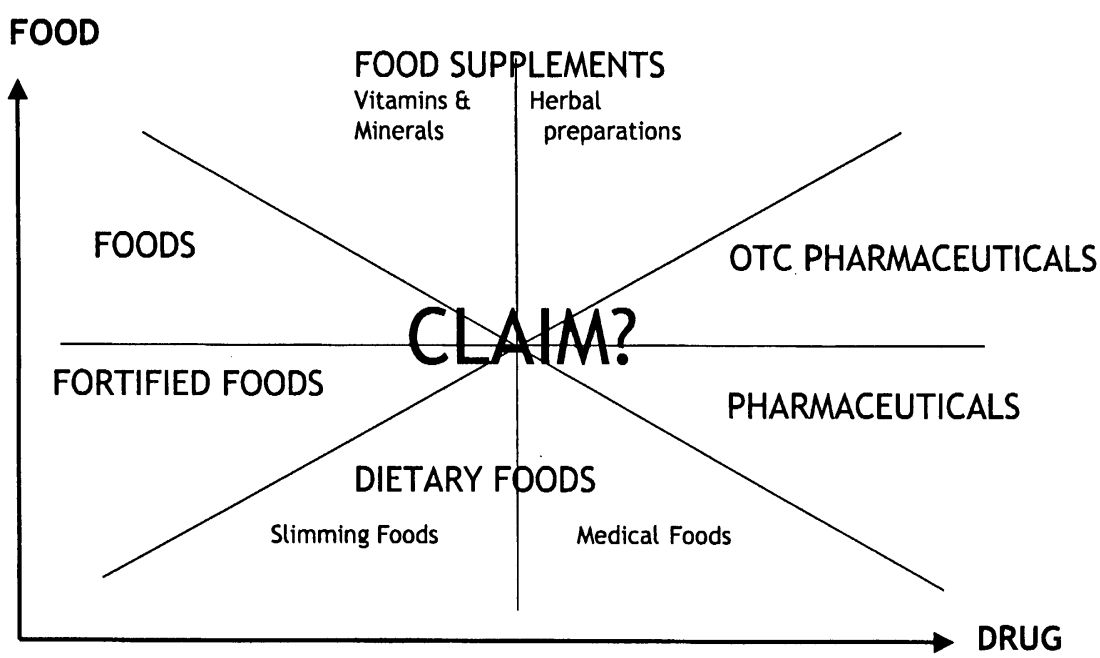

Fig. 1. Food health claims: the potential for problem 'grey areas' when making claims.

areas that give rise to problems. Most often, the medicinal dimension is quoted, but there are other sectors where established legal rules can result in conflict.

Notwithstanding the proposals that may be made in the EU Commission Discussion Paper later this year, the food industry and regulators have reached a general consensus that the European 'Labelling' Directive (2000/13) should be revised to take account of health claims. Currently, there is no legal definition of what a 'health claim' is at either Member State (National) or EU level, but a definition has been proposed in the draft Food Law Regulation (COM 2000716 final) where:

'Food' (or 'foodstuff') means any substance or product, whether processed or unprocessed, partially prepared or unprocessed, intended to be, or expected to be ingested by humans

This draft proposal includes water, without prejudice to Directives 98/83/EC and 80/778/EEC and excludes medicinal products (Directive 65/65/EC), despite the formers specific mention of medicinal claims, and the latter's all embracing stance that would encompass food, if a disease risk reduction claim is made. These individual issues are discussed further below.

Codex Alimentarius has provided useful claims for the food sector, and these have been taken on board in some of the Codes of Practice listed in Table 1 and referred to above. Usually the more liberal Codes have adopted the view that a health claim means 'any representation that states, suggests or implies that a relationship exists between a food or a constituent of that food and health.' Specifically, the two Codex claims are:

Enhanced function claims:

concern specific beneficial effects of the consumption of foods..........do not include nutrient function claims.........relate to a positive contribution to health...etc

Reduction of disease risk claims:

......relate to the consumption of a food or food constituent in the context of the total daily diet that might help reduce the risk of a specific disease or condition

It is easy to see where the conflict with medicinal claims will arise when disease risk reduction claims are proposed for food. The Medicinal Products Directive $(65 / 65 / E C)$ states that any substance presented for treating, or preventing disease, and/or by virtue of its function is administered with a view to correcting, restoring or modifying a physiological function will be a medicine. Health claims that mention reducing the risk of disease will be in direct conflict with these basic tenants. There is the possibility that when a disease risk reduction claim is concerned with a biomarker, for example, LDL cholesterol rather than cardiovascular disease itself, disease risk reduction may indeed be possible. However, we need to be aware that consumers need clear health messages, rather than phrases specifically constructed to meet or circumvent the requirements of outdated legislation. When we consider the age of the Medicines Directive, created in the early 1960 's, it is very difficult to see how such legislation can be entirely appropriate some 40 years later given the huge advances that have taken place regarding the understanding of the effects of nutrition on health. At the moment, all foodstuffs bearing health or diseaserelated claims could be considered as medicinal irrespective of their form or efficacy, and all such foodstuffs can be likewise considered as medicinal based on their physiological effects. 
It is unfortunate that in EU legislation, health claims are defined in terms of what they cannot do rather than adopting a positive, or at least an initial neutral attitude and approach that would lead to fresh thinking.

The Misleading Advertising Directive (84/450) does not directly refer to claims, although it is generally acknowledged that claims fall under its scope. Including Directives 65/65 and 84/450, there are a total of seven EU Directives that refer to claims. Each of these, apart from one (Directive 80/778/EEC on Natural Mineral Waters), deals with claims in the negative sense, or more precisely, what it is not permitted to do. These Directives are:

- Labelling, Presentation \& Advertising of Foodstuffs Directive 2000/13/EC (former 79/112)

- Directive 65/65 Medicinal Products

- Dietary Foods for Special Medical Purposes Directive 1999/21 (PARNUTS)

- Misleading Advertising Directive 84/450

- Directive 76/768 on Cosmetic Products

- Directive 89/552 on Television Broadcasting Activities, as amended by $97 / 36$

- Directive 80/778/EEC on Natural Mineral Waters

For example, the 'Labelling' Directive 2000/13/EC Article 1 states that the labelling and methods used must not:

'(a) be such as could mislead the purchaser to a material degree, particularly:

(i) as to the characteristics of the foodstuff and, in particular, as to its nature, identity, properties, composition, quantity, durability, origin or provenance, method of manufacture or production,

(ii) by attributing to the foodstuff effects or properties which it does not possess,

(iii) by suggesting that the foodstuff possesses special characteristics when in fact all similar foodstuffs possess such characteristics'

In addition, the labelling and methods used must not: (b) subject to Community provisions applicable to natural mineral waters and foodstuffs for particular nutritional uses, attribute to any foodstuff the property of preventing, treating or curing a human disease, or refer to such properties'

The Dietary foods for Special Medical Purposes Directive 1999/21/EU (FSMP) does offer an opportunity for these very specific foods to make health claims. Product labelling has to include the following statement: 'for the dietary management of ....... where the blank is filled with the name of the disease(s), disorder(s) or medical condition(s) for which the product is intended for use under medical supervision'

Promotion of the product is permitted to health professionals only and not directly to the patient, therefore such products and claims do not offer a viable route for the promotion of food health claims in the general sense, to the public.

Although not directly related to food and health claims, it is useful to note that Article 6(3) of Directive 76/768 on Cosmetic Products mentions harmonised action against false claims:

'Member States shall take all measures necessary to ensure that, in the labelling.........advertising of cosmetic products, text, names, trade marks, pictures ........ are not used to imply that these products have characteristics which they do not have'

Similarly, Directive 89/552 on Television Broadcasting Activities (as amended by 97/36) prohibits linking the attributes of alcohol to enhanced physical performance, to driving (vehicles), towards social or sexual success, therapeutic qualities or by implying that alcohol is a stimulant, a sedative or a means of resolving personal conflict.

However, when we look at the specific Directive that deals with mineral water, there is a very different approach.

If the mineral water has been assessed as possessing the property claimed in accordance with analysis and 'pharmacological, physiological and clinical examination, as appropriate,' in accordance with Article 9 2(c) of Directive 80/778/EEC on Natural Mineral Waters, Member States may authorise the following health claims, provided no reference to the prevention, treatment or cure of human disease is made:

'may be diuretic'

'may be laxative'

the indication 'stimulates digestion'

the indication 'may facilitate the hepato-biliary functions'

or similar indications

It is clear that Europe does urgently need changes to the Labelling Directive (2000/13/EC) to include a definition of food, a definition of the different nutritional and health claims and to address the issue or disease risk reduction by nutrition in the light of disease prevention by medicines. There will also be changes required to other central (Medicinal Products Directive 65/65/EC) and peripheral (Directive 80/778/EEC on Natural Mineral Waters) legislation.

Of course, hand in hand with changes to the legislation must come changes in the way health claims are 
promoted to the consumer, and the need for an agreed set of general principles for making health claims. Dealing first with Marketing, the published Codes of Practice drawn up by the Confederation of the Food \& Drink Industries of the EU (CIAA) (7) Code of Practice and the UK Joint Health Claims Initiative (JHCI) (4) set out the following areas that must be taken into account:

- Consumer perception of the health claim

- Should be complete, truthful and not misleading

- They must relate to the food as part of the overall diet

- Over-consumption not to be encouraged

- Must be consistent with the scientific evidence

- Must not denigrate other foods or their diet contribution

- No indication that the claim is the only solution

Food companies should remember that there are other ways to communicate the health claim, other than the label, such as help lines, leaflets and press advertising always bearing in mind that these are also subject to specific controls.

These Codes also lay down general principles for making food health claims as follows:

- Be in line with the scientific substantiation and be truthful, not misleading, exaggerated, nor deceptive

- The Company is responsible for their justification on the basis of sound scientific evidence

- The claim must be supported by the scientific evidence by being appropriate and must be available to the Authorities

- The food or ingredient is the subject of validation where amounts need to be indicated, with efficacy until end of shelf life

- Claims must be justified in the context of the whole diet and applicable to the amount of the food normally consumed

The quality of the scientific substantiation of the evidence behind food health claims can vary enormously. Proposals promulgated by the Council of Europe, the CIAA and many of the EU National Codes of Practice, including the UK include the following list of requirements:

- The food company marketing the product is responsible for ensuring that overall, claims validation has been carried out

- The food health effects are real and acceptable by scientific consensus and/or by human clinical trials

- The evidence must be consistent, plausible, multi-sourced and be able to meet accepted stan-
Table 2. Food health claims: potential areas for generic food health claims in the UK.

- Fruit \& vegetables and the reduced risk of heart disease

- Fruits \& vegetables and the reduced risk of cancer

- Low fat, reduced fat, saturated, mono-unsaturated fat and reductions in blood cholesterol levels

- Long chain $n-3$ fatty acids/oily fish and a healthy circulation

- Soluble fibre and reductions in blood cholesterol

- Complex carbohydrates and a reduced glycaemic response

- Dietary fibre and a healthy digestive system

- Pre- and probiotics and a healthy digestive system

- Low/reduced sugar (and sugar alcohols) and healthy teeth

- Low/reduced salt and reduced risk of high blood pressure

- Calcium \& vitamin D and the maintenance of healthy bones

- Iron and healthy blood

- Folic acid and healthy foetal development

- Vitamin B12 and health maintenance for vegetarians

dards

- The totality of the evidence is required and includes peer-reviewed literature, in vitro studies, animal models, clinical studies and epidemiology

- Where human studies are carried out, there is a need to ensure that a representative population/ group is used together with recognised and validated methods in an appropriate time frame

- The health effects must be quantitatively, statistically and biologically significant

- If the composition of the food changes, additional checks are required to ensure validity of the claim

- The functional ingredients must be present in the appropriate quantity and form for the duration of the shelf life

- Recommendations for the serving size are required taking consumption pattern, conditions of use and the nutritional intake of the population group/sub group

The UK has adopted a similar approach to that of the US FDA in proposing that food health claims are controlled by a list of so-called 'generic' claims, acceptable with no further scientific support required for their use on individual products. However, generic claims must have been agreed by a general scientific consensus and this is achieved by an on-going review by an independent Expert Committee. Table 2 sets out the areas being considered for generic food health claims that by the end of 2001 should result in a list of about 10 areas where such claims can be made.

In conclusion, the use of National voluntary Codes 
of Practice, especially those devised using at least a tripartite forum of the Authorities, Consumer Associations and the Food Industry, can encourage the prudent and responsible application of scientific evidence to the promotion and marketing of foods with health claims. There is a need for the EU to revise the Labelling (2000/ 13) and the Medicinal Products (65/65/EU) Directives to clarify food health claims. National voluntary codes aim to help clarify the extent of existing food and borderline products' legislation providing the mechanism for pre-market advice, scientific evaluation and preclearance of health claims and we look forward to the publication later this year of the EU Commission Discussion Paper on health claims. We hope that it will encompass the best ideas from the many Codes and Guidelines that are now available.

The burden of responsibility for the use and substantiation of food health claims lies with the food industry, but the industry needs to be able to communicate the proven benefits of health claims effectively to the average consumer to permit the marketing of bona fide foods with health claims.

\section{REFERENCES}

(1) Japan Health Food \& Nutrition Food Association, 6-6, Jingumae 2-chome, Shibuya-ku, Tokyo 150-0001, Japan.

(2) Denmark, A European base for functional foods, 2nd edition, October 1997, Slotsholmsgade 12, DK-1216 København, Denmark.

(3) Code of Practice, Assessing the scientific evidence for health benefits stated in health claims on food and drink products, 1998, Voedingscentrum, PO Box 85700, 2508 CK, The Hague, The Netherlands.

(4) Code of Practice on health claims on foods, The Joint Health Claims Initiative, c/o The Leatherhead Rood Research Centre, Randalls Road, Leatherhead, Surrey, UK, KT22 7RY.

(5) Revised approved final draft version of the Council of Europe, Guidelines on Health Claims for functional foods, 7.12.00, submitted by Prof M. Roberfroid (rapporteur) arising from the 3rd meeting, Strasbourg, November 2000, ad hoc group-functional food.

(6) Letter to manufacturers regarding Botanicals and other Novel Ingredients in conventional foods, 31.1.01, Dr Christine Lewis, Director of the Office of Nutritional Products, Labelling, and Dietary Supplements, FDA Centre for Food Safety and Applied Nutrition.

(7) Code of Practice on the use of health claims, Confederation of the Food and Drink Industries of the EU, Avenue des Arts, 43, B-1040, Brussels. 